\title{
Trends in bariatric surgery in Canada, 1993-2003
}

The annual number of bariatric surgeries in Canada (excluding Quebec and rural Manitoba) has risen from 78 in 2000-01 to over 1100 procedures in 2002-03, according to the Canadian Institute for Health Information Discharge Abstract Database. Studies have shown that patients

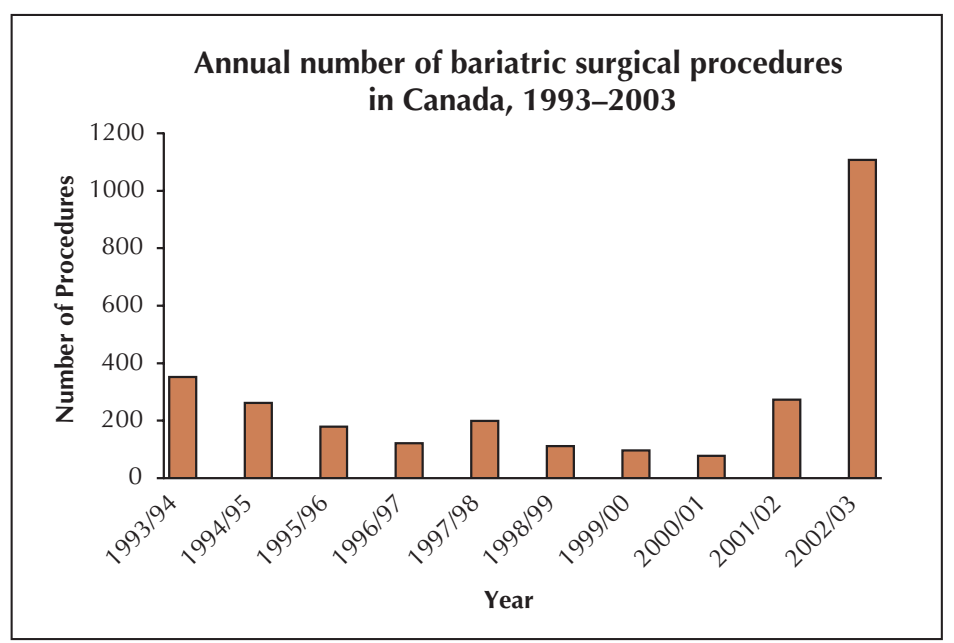

Hypertension

\section{Feeling the pressure}

New recommendations urge physicians to diagnose and manage hypertension more quickly to prevent complications. It now takes up to 6 months from initial presentation to diagnosis, which delays treatment and increases the possibility of complications.

The 2005 Canadian Hypertension Education Program (CHEP) Recommendations advocate quicker diagnosis in physicians' offices and by the use of home and ambulatory blood pressure monitors (www .hypertension.ca). The recommendations set out an algo+ rithm for expedited diagnosis based on blood pressure levels and, if appropriate, other medical conditions.

For example, diagnosing level 1 (mild) hypertension (systolic 140-160, diastolic 90-100) would entail 2 visits to a physi- initially lose between 35\%-60\% of baseline body weight and maintain weight reductions of approximately $16 \%$ after 8 years. ${ }^{1,2}$ No prospective, randomized trial has demonstrated a reduction in cardiovascular morbidity and mortality with bariatric surgery, although re-

cent observational data suggest beneficial effects on these outcomes. ${ }^{2-4}$ Bariatric surgery is currently indicated in severely obese individuals with a body mass index (BMI) of $40 \mathrm{~kg} / \mathrm{m}^{2}$ or a BMI of $35 \mathrm{~kg} / \mathrm{m}^{2}$ in the presence of obesity-related comorbidities. Raj S. Padwal and Richard Z. Lewanczuk, Edmonton, Alta.

\section{References \\ 1. Brolin RE. Bariatric surgery and long-term control of morbid obesity. 7AMA 2002;288:2793-6. \\ 2. Sjostrom L, Lindroos AK, Peltonen $\mathrm{M}$, Torgerson J, Bouchard C, Carls- son B, et al. Lifestyle, diabetes and cardiovascular risk factors 10 years af- ter bariatric surgery. $N$ Engl 7 Med 2004:351:2683-93. \\ 3. Buchwald H, Avidor Y, Braunwald E, Jensen MD, Pories W, Fahrbach K, et al. Bariatric surgery. A systematic review and meta-analysis. $7 A M A$ 2004;292:1724-37. \\ 4. Christou NV, Sampalis JS, Liberman M, Look D, Auger S, McLean AP, et al. Surgery decreases long-term mor- tality, morbidity, and health care use in morbidly obese patients. Ann Surg 2004;240:416-24.}

cian and 1 week of home blood pressure monitoring or 24 hours of ambulatory monitoring.

"We now know from a number of studies that complications from high blood pressure can occur sooner than we would have thought," says Feldman (Lancet 2004;363:2022-31).

About $43 \%$ of Canadians with hypertension are never diagnosed. Among the $23 \%$ of Canadian adults who are diagnosed with hypertension, only $16 \%$ are treated and controlled.

This "substantial gap" in detection and diagnosis must be addressed, says Dr. Ross Feldman, co-chair of the CHEP recommendations task force.

Feldman acknowledges the current debate over the accuracy of blood pressure monitoring equipment (CMA7 2002; 166[9]:1145-8) and advises purchasing equipment that is en- dorsed by a reputable organizations and teaching patients how to use it properly.

The 2005 recommendations also support the "increasingly held belief" that, in general, no single class of antihypertensive drug provides substantial benefits over others. The important thing is to lower blood pressure. "People have made big deals about mostly secondary endpoints. The CHEP network decided it's more important to lower blood pressure."

The move to expedite diagnosis follows a Lancet study (2005; $365: 217-23$ ) predicting that 1 in 3 adults - 1.56 billion people will have hypertension by 2025 .

The CHEP guidelines are funded through the Canadian Hypertension Society by Health Canada and 12 pharmaceutical companies. - Barbara Sibbald, CMAJ 